\title{
Literatura e ética: notas para um diálogo que não se acaba
}

\author{
Rejane Pivetta de Oliveira ${ }^{1}$ \\ Ricardo Araújo Barberena ${ }^{2}$
}

Se aceitarmos como válido o princípio ético fundamental - a ação para o bem, nos termos de Aristóteles (1973) - devemos colocar sob essa perspectiva algumas questões que cercam a discussão proposta no presente número da Estudos de Literatura Brasileira Contemporânea: i) com que propósito uma revista acadêmica conclama estudiosos e pesquisadores a mobilizarem esforços para a reflexão sobre as relações entre literatura e ética?; ii) em que termos a ética é uma questão que importa aos estudos literários?; iii) que questões emergem quando se trata de pensar as relações entre literatura e ética?; iv) do que a literatura é capaz diante da crise ética? Tais perguntas, de respostas imprecisas e insuficientes, valem pelo debate que ensejam, no horizonte do qual esperamos alcançar algum ponto de entendimento das complexas relações entre literatura e ética. Para início de conversa, vale desdobrar algumas perspectivas de análise atinentes aos tópicos acima elencados.

\section{Um chamado para a escrita}

O convite para a reflexão sobre o tema "Literatura e ética", a despeito de decisões editoriais que marcam o perfil e a identidade dos periódicos, situase em um contexto mais amplo, relativo a um momento histórico e a discussões emergentes no campo da crítica acadêmica. Editores, críticos, pesquisadores e intelectuais não apenas delineiam os territórios da pesquisa, como também assumem posições teóricas e políticas, sobretudo quando se trata de participar dos debates sobre problemas que insistem em assombrar as sociedades contemporâneas, como violência, autoritarismo, segregações, desigualdades e injustiças de toda ordem. O enfrentamento desses impasses ganha uma dimensão ética quando o questionamento se

\footnotetext{
${ }^{1}$ Doutora em teoria da literatura e professora do Centro Universitário Ritter dos Reis (UniRitter), Porto Alegre, RS, Brasil. E-mail: pivetta.rejane@gmail.com

${ }^{2}$ Doutor em literatura comparada e professor Pontifícia Universidade Católica do Rio Grande do Sul (PUC-RS), Porto Alegre, RS, Brasil. E-mail: ricardobarberena@ hotmail.com
} 
volta para as formas de ocupação do espaço social e para o sentido das práticas humanas com vistas ao bem comum, evitando lugares de privilégios e hierarquias na distribuição de direitos e benefícios.

Se quisermos saber, no âmbito da crítica literária brasileira, especialmente a produzida no ambiente acadêmico, que notícias ela nos traz dos grandes desastres éticos da civilização, e de que maneira se posiciona nos "momentos de perigo" - aqueles que ameaçam tanto o passado como o presente de sucumbirem à dominação dos vencedores, como anuncia Walter Benjamin (2012) em suas teses sobre a História -, uma pesquisa nos principais periódicos da área publicados no Brasil poderia dar alguma medida de sua participação no debate sobre as relações entre literatura e ética. Como essa seria uma pesquisa de largo fôlego para os objetivos deste texto, uma rápida busca no sistema da própria Estudos de Literatura Brasileira Contemporânea pela palavra "ética" localiza artigos das edições de 2014, 2015, 2016 e 2017, para ficarmos nos anos mais recentes e no âmbito específico do debate sobre a realidade cultural brasileira. Esses textos inserem-se em números temáticos sobre "Literatura e ditadura", "Espaço e subjetividade", "Literatura e periferia" e "Espaços do literário", propondo discussões em torno de representações de gênero e sexualidade, produções literárias fora do establishment, autoria feminina, recuperação da memória histórica ameaçada de esquecimento, entre outras. A mostra, mesmo que não exaustiva, é suficiente para percebermos a incidência do tema ético nas abordagens críticas da literatura brasileira.

Nesses termos, o convite ao debate sobre as problematizações éticas a que a literatura é capaz de dar forma e transmitir ao tempo presente vem na esteira de preocupações já assinaladas em contribuições anteriores à revista, que esta edição reforça com provocações mais explícitas: em que termos a literatura é capaz de configurar relações éticas e qual seu poder de intervenção no cenário de barbárie e falência moral contemporânea? Mesmo que as respostas a essas questões não encontrem garantia, abrir espaço para a reflexão desses e outros tópicos cumpre a tarefa de instigação crítica e, assim, logra escapar ao conformismo, no intuito de fazer valer a promessa ética da realização do bem.

Todavia, cabe ressalvar que, na realização do "sumo bem", como postulou Aristóteles (1973, p. 249), é necessário ter em conta as regras e as prerrogativas que definem o que é bom para as pessoas em geral. Sabemos que, na democracia grega, o interesse pelas boas condutas dizia 
respeito somente aos cidadãos, aqueles que dispunham de recursos e tempo livre para falar nas assembleias em praça pública, com poder de decidir sobre os rumos da polis, confiscando de boa parte do "povo" o direito à voz. Numa sociedade assim dividida, é de se suspeitar que a distribuição do bem não seja exatamente igualitária. Nessa medida, expandir o debate e ampliar o espaço da crítica será sempre um gesto de resistência e de esperança na fundação de uma nova democracia, como horizonte de participação coletiva e realização do bem comum.

\section{Estudos literários e razões éticas}

O debate envolvendo literatura e ética aprofunda-se na medida da indagação sobre o lugar e as funções do literário no contexto contemporâneo, tarefa que por certo cabe à crítica problematizar. A questão, parece-nos, não pode ser tratada com base na defesa de um ideal ético pertencente à literatura de maneira inerente e universal. A dimensão ética jamais pode ser discutida nos termos de prerrogativas e normas estabelecidas a priori como valor. A ideia de um primado ético da literatura incorre no perigo de reforçar concepções essencialistas, forjadas no seio de formações culturais assentadas em modelos hegemônicos de civilização e racionalidade. Um problema ético certamente se instala quando paradigmas supostamente universais são sobrepostos a contextos e referências marcados pela diferença, não assimiláveis aos padrões legitimados, sejam estéticos, sociais ou culturais.

Muito da discussão sobre a função da literatura passa pela alegação de seu poder emancipatório e do dito valor estético, enquanto qualidades essenciais da obra, encarregadas de oferecer patamares mais elevados de compreensão sobre os seres humanos e a sociedade. Contudo, essa atribuição pedagógica à literatura é feita sob um regime de divisão social que fixa competências, posições e identidades dos sujeitos: letrados e iletrados; capazes e incapazes; iniciados e ignorantes; intelectuais e trabalhadores etc. As formas de expressão da subjetividade e da experiência, que Jacques Rancière (2009) situa no campo da produção sensível, estão submetidas a hierarquias e a um regime de "partilha", que tanto significa participação comum como divisão dos modos do fazer e do dizer.

Assim, a postulação ética da literatura, antes de referir-se a qualquer conteúdo humano de validade universal, talvez comece por concebê-la 
fora do círculo daqueles que reivindicam para si o direito de proclamar a primazia do literário, colocando-se no papel de intérpretes e apreciadores autorizados, seus "proprietários" naturais. Entender a literatura como um direito, conforme propõe Antonio Candido (1995), não deveria se transformar em um "imperativo categórico", sem antes indagarmos em nome de que ordem de divisões tal direito se institui.

Se levarmos ao limite a demanda da ação para o bem exigida em toda relação ética, a pergunta sobre a função da literatura não estaria direcionada às qualidades intrínsecas da obra, ou a um conteúdo que lhe seja essencial, mas, antes, consideraria a própria existência pública da literatura, ou seja, o fato de não se reduzir a um pequeno círculo privado de obras, autores, leitores e instituições, nem se contentar com os limites da sua institucionalização, mas expandir seu alcance, nas práticas literárias efetivas que dizem das formas de expressão e dos modos de vida de uma ampla comunidade de sujeitos. Em sua dimensão ética - e, portanto, política - a literatura demanda um olhar para fora, além de si, fazendo perceber as divisões e as posições sociais, em meio às quais ela própria se estabelece.

Vistas tais questões como notas para uma "conversa infinita" sobre as relações entre literatura e ética, resta saber que traços dessa relação são tratados pelos artigos que compõem a presente edição.

\section{Temas e perspectivas éticas em debate}

Os artigos que compõem esta edição da Estudos trazem à baila algumas questões problematizadoras das relações entre literatura e ética.

No artigo "A (po)ética de Carolina Maria de Jesus e o direito à escritura", a questão ética é abordada a partir de questionamentos sobre o direito de narrar dos sujeitos subalternos, em contraponto ao silêncio e às narrativas dominantes que falam pelo outro, sob o ponto de vista do discurso colonial. A autora põe em diálogo as posições de Antonio Candido sobre o direito à literatura, as reflexões de G. Spivak sobre a necessidade de o intelectual estar consciente dos impasses inerentes ao seu lugar de fala sobre o outro, e as problematizações sobre o direito de narrar postas por Homi Bhabha. No contraponto das ideias, salienta que, além de reivindicar o acesso de todos aos textos literários, é preciso romper com as distinções canônicas entre literatura popular e erudita e, de outra parte, não limitar o subalterno ao lugar de representado, para 
que possa ele mesmo ser o enunciador de sua condição. Nesses termos, fazendo "soar" a contrapelo a voz do sujeito periférico, o artigo examina a obra de Carolina Maria de Jesus, Quarto de despejo, como um locus de enunciação em que sua autora, negra e moradora da favela do Canindé, em São Paulo, expõe "sua posição de subalternidade". Assim, mais que o "direito à literatura", a reivindicação ética reside no direito de narrar, por meio de uma escritura (po)ética, em que o político e o estético atuam para derrubar muros e as sombras que se projetam na história.

De que forma o escritor elabora seu projeto literário na relação com a sociedade e a ideia de nação? Qual seu lugar e sua função como intelectual? Tais questões são discutidas no artigo "Ruffato: um escritor e um projeto de nação", que analisa "cenas de leitura" no texto "Até aqui tudo bem. Como e porque sou romancista versão século XXI", de Luiz Ruffato, comparativamente ao conhecido texto de José de Alencar, escrito no século XIX. A presença do livro e da tradição letrada em ambos os textos diz sobre a formação literária dos escritores e as concepções estéticas norteadoras da obra de cada um deles. Se Alencar está vinculado ao projeto romântico de contar a origem da terra brasileira, criando um mito fundacional, Ruffato trabalha com a fragmentação, com mobilidades geográficas e culturais, ocupando-se da trajetória dos trabalhadores urbanos migrantes de classe média baixa, num mosaico de histórias e textos, conforme ilustra Eles eram muito cavalos, obra emblemática na trajetória do escritor. Conforme apontam as autoras, Ruffato recupera, no século XXI, questões que sempre foram alvo da reflexão de escritores e críticos brasileiros, a partir de um projeto de escrita que amplia as discussões sobre os novos pertencimentos da literatura e os significados de ser escritor no mundo contemporâneo e em um país como o Brasil, situado na "periferia do mundo".

Em "A hora da estrela: por uma leitura nordestina", o questionamento ético começa por desconstruir os lugares sagrados da literatura e da crítica canônicas. Trata-se de colocar sob suspeita os processos de semiotização da realidade, que reduzem o outro a uma representação homogeneizante, interpretada em termos imanentes. $\mathrm{O}$ autor propõe a leitura de Macabéa a partir de uma "crítica nordestina", que resiste aos substancialismos identitários, em favor da abertura para a diferença e a alteridade. Em sua análise, o autor reverte o ponto de vista crítico que sempre viu nas indagações metalinguísticas do romance de Clarice Lispector uma contraposição à literatura-verdade da década de 1970. 
Trata-se de colocar em perspectiva o lugar que o discurso do narrador, Rodrigo S.M., reserva à alteridade do outro, ao que responde: "Macabéa e seu Nordeste natal estão numa simbiose sem fora, obedientes a uma tradição discursiva estigmatizante que homogeneiza a diferença, em hipótese alguma questionada, duvidada, problematizada pela ironia do narrador". Questionar o lugar apriorístico e tautológico a que o discurso narrativo de $A$ hora da estrela submete Macabéa é a pedra de toque da crítica intercultural e política proposta pelo autor, salientando que a literatura está inserida em relações sociais contraditórias e desiguais.

As questões éticas estão no centro da trama do romance Divórcio, de Ricardo Lísias, analisadas no artigo "Discutindo Divórcio entre literatura, jornalismo e ética: um caso não só literário". O romance foi alvo de intensas polêmicas no meio literário, ultrapassando os limites estritamente estéticos para desembocar na relação direta com a vida pessoal do escritor. A experiência traumática de divórcio, motivada pela traição da ex-mulher, vivida pelo autor, é o mote que serve à construção da trama narrativa, em que fato e ficção não se distinguem, antes fazem parte de um mesmo espetáculo, arquitetado seja nas páginas de um romance ou nas de um jornal, com base em procedimentos similares: a matéria narrada é obtida por meio de relações escusas com suas "fontes". O artigo explicita as articulações da ficção com os problemas éticos envolvidos na conduta dos jornalistas, tomando como referenciais o caso Watergate, nos Estados Unidos, e o caso Collor de Mello, no Brasil, ambos envolvendo o papel das fontes na obtenção das informações, muitas delas vazadas por meio de procedimentos inescrupulosos. Para os autores, a escrita de Lísias - que também não escapa ao questionamento ético, uma vez que a matéria ficcional é composta de trechos do diário da jornalista e ex-mulher do escritor, o qual não estava autorizado a publicá-los - denuncia os jogos de engano do mundo jornalístico e do ambiente cultural brasileiro, que à literatura cabe desmascarar. Todavia, vale lembrar, a própria literatura não está imune a esses jogos, sob a aura da ficção.

Tendo como objeto de análise o último livro de Hilda Hilst, o artigo "Filosofia cínica contemporânea e dispositivos éticos de resistência em Mula de Deus, de Hilda Hilst" apresenta uma importante reflexão crítica sobre o imaginário da velhice, da finitude humana e das tensões cínicas de uma pragmática animista da vida humana. Ao relativizar conceitos norteadores da metafísica tradicional, o texto deflagra uma série de questionamentos motivados pela filosofia cínica. Nesse sentido, o 
conceito de parrésia é fundamental enquanto aparato epistemológico. A estratégia socioestética da parrésia é problematizar a dimensão da perspectiva cínica, postura semelhante àquela da antiguidade clássica, capaz de desconstruir universos existenciais disfuncionais, de modo irônico, disfêmico, grotesco e risível. Tais reordenações cínicas supõem a presença de sujeitos que atuem como agentes sociais ativos nos fenômenos de coexistência humana e ecocrítica. A partir dessa perspectiva filosófica, o poema "Mula de Deus" é discutido no tocante à noção de que o ser humano, frente à velhice e à morte psicossocial, e até mesmo física, possui a capacidade de posicionar-se de modo cínico, com a esperança, talvez, de minimizar a dependência de supostas consolações metafísicas. Esse sujeito cínico passa a exigir respostas éticas de sua rede coexistencial para que sua dignidade humana seja assegurada.

“Um verdadeiro purgatório: Leite derramado em diálogo com A divina comédia" desenvolve uma crítica intertextual entre o romance Leite derramado, de Chico Buarque, e A divina comédia, de Dante Alighieri. A prosa do escritor brasileiro apresenta uma narrativa construída a partir de um narrador-personagem, Eulálio d'Assumpção, no limiar entre a vida e a morte, em um hospital público - representação de uma espécie de purgatório terreno. O purgatório metaforiza um intervalo, relaciona-se ao entremeio, a trânsitos e passagens, é um momento de espera, instância entre uma fase pretérita e uma fase vindoura. Quanto à geografia, ou seja, ao espaço, se o céu está situado no alto e o inferno no baixo, o purgatório está entre o baixo e o alto. O purgatório, reinscrito no romance, longe de ser uma mera repetição de um clássico universal, mostra a singularidade da obra de Chico Buarque. O ensaio desenvolve uma discussão crítica acerca do cenário, os sofrimentos e as lamentações de Eulálio, bem como a antroponímia dos personagens que retoma o imaginário ficcional dantesco. Ao longo da reflexão, destaca-se a problematização do uso da carnavalização literária no romance. Em estágio de purgação, o narradorpersonagem segue do paraíso da infância ao inferno da decadência e, numa espécie de confissão involuntária, expõe pensamentos e atos politicamente incorretos que desabonam os representantes de uma elite decadente no Brasil.

As indagações propostas nos ensaios aqui apresentados articulam uma série de abordagens sobre o tema da ética, no âmago do fazer literário de diferentes autores e autoras da literatura brasileira contemporânea, não excluindo o diálogo com vozes de outros tempos e 
lugares. O que podemos esperar, depois desse percurso, é que a ética não seja apenas um elemento acessório nas reflexões sobre o literário e jamais inócuo à vida real e ao momento presente.

\section{O que resta à literatura}

Estamos em 2017. Esse ano será julgado pelo futuro que se aproxima. Donald Trump assumiu a presidência após o mandato do primeiro presidente negro da história dos Estados Unidos. Na França, antigo berço iluminista, Marine Le Pen segue triunfante os passos de consolidação de um feroz radicalismo conservador. O Brasil passa por tempos conflituosos de fisiologismo e retrocesso dos direitos dos trabalhadores. Já em terras argentinas, quem dá o tom é o projeto neoliberal de Mauricio Macri. Sim, são tempos estranhos.

Como fica a literatura nesse cenário? Qual o seu lugar? Qual antídoto ela pode apresentar? Talvez seu papel seja justamente um ir-para-alémde-si. Enquanto espaço de resiliência e resistência, a literatura ainda se configura como uma prática de experimentação radical da alteridade. Quando pensamos, em termos quase arquetipais, na figura do escritor, somam-se figurações de um sujeito declinado na classe média, heterossexual, branco. Os leitores projetam um ethos pré-discursivo para o autor que pode influenciar na recepção do livro. Desse modo, hoje, em nossa estranha contemporaneidade, devemos, acima de qualquer manobra linguística, refletir sobre a ausência de escritoras/escritores periféricos nos programas das disciplinas e nos auditórios das nossas faculdades. Refletir sobre os traumas de hoje é pensar sobre os traumas do transitar. Cabe, principalmente aos professores universitários, a construção de uma espécie de curadoria acadêmica, na qual vozes de múltiplos quadrantes identitários estejam contemplados.

O contrabando de saberes e signos possibilita a constante descentralização de um antigo escudo conservador. Se aceitarmos a hipótese de que a literatura nos humaniza, talvez seja possível darmos mais um passo: ela também nos transforma em seres reparadores. Nesse sentido, é sempre pertinente retomar a epígrafe saramaguiana: "Se podes olhar, vê. Se podes ver, repara". Sem dúvida, alcançamos facilmente o primeiro estágio fenomenológico no qual olhamos para as identidades subalternizadas, mas resta uma ultrapassagem ontológica para que possamos realmente vê-las. Fica um messiânico devir a ser 
protagonizado pelo observador, pois ele necessita reparar (arrumar, corrigir, reorganizar, transformar) o que foi visto numa primeira instância da sua visão. E é aqui que se indaga nossa fetichização da dor do Outro e a efetiva modificação de sua realidade. Vivenciar a literatura é, para além das particularidades formalistas, um exercício da desconstrução dos aparatos ególatras da contemporaneidade. Esse ato tem muitos significados. Migrar em direção ao desconhecido é uma espécie de encontro marcado com a materialidade narrativa da alteridade: um mundo cartografado pela voz do Outro. Longe do egocentrismo crônico, a universidade hoje deve lançar um olhar no qual a literatura pode ser entendida como um espaço que abriga histórias. É como se o pesquisador navegasse por "fios de histórias" - oceano idealizado por Salman Rushdie, no qual as águas ficam às vezes poluídas, grossas e lentas, parecidas com xarope, pois essa situação é causada por uma rolha que impede o fluxo livre das histórias. Cabe a nós diariamente retirarmos essa rolha canônica e institucional.

Se socialmente já consolidamos uma ética médica, chegou a hora de instituirmos uma ética literária capaz de movimentar as estórias ancoradas nos cárceres anônimos dos sujeitos "comuns" e alcançarmos uma circulação em momentos desprovidos de sacralização aurática. Num humilde e empoeirado apartamento, é possível encontrar um enredo-devida clandestina que merece sair pela porta de forma a chegar aos ouvidos de uma inusitada alteridade. Sem uma efabulação democrática, não resistiremos. Desde os primatas, a narratividade se desenvolveu em nossa espécie como técnica de sobrevivência. Afinal, onde está o real humano? Nas ficções que o constituem. Para nós, humanos, a ficção é tão presente quanto o chão que pisamos. Ela é esse próprio solo. $\mathrm{O}$ nosso suporte no mundo. Somos uma "espécie fabuladora", um "animal contador de histórias". A ficção nos torna humanos. Melhor: somos, na definição de Johnathan Gottschall, homo fictus (homem ficcionalizador), pois a ficção é para os humanos como a água é para os peixes totalmente envolvente e não muito perceptível. Assim como o romancista faz com o nome de seus protagonistas, os pais hesitam, por vezes, em relação ao nome que darão aos filhos. Nosso nome é a nossa primeira ficção. Criado o nome da personagem, ela segue sua irremediável trama existencial nos mais variados quadrantes identitários. $\mathrm{E}$ a rede narratológica segue: qual a história do sobrenome? Qual a história do local de nascimento? Qual a história da data do nascimento? Devemos 
estar atentos para explorar a exterioridade do outro como uma jornada de aprendizagem testemunhal. As fábulas da alteridade são uma possibilidade de conhecimento para um Eu-que-escuta.

Em tempos em que muros se levantam e extremismos conservadores se consolidam, cabe a nós, num ato de resiliência, o exercício do questionamento dos limites beletristas de um cânone excludente. Anos terríveis se avizinham e lutaremos para que a literatura esteja no front em que sempre se mostrou uma valente guerreira: na trincheira pela liberdade. Afinal, como adverte Manoel de Barros, "Pensar é uma pedreira. Estou sendo". Um pensar doloroso e poroso que se dobra sobre si mesmo num pedregoso movimento. Para compreender esse fluxo de fragmentos, é fundamental que estejamos atentos à voz passiva perifrástica no tempo presente: "Estou sendo". Aqui o inacabado do gerúndio ensina muitas coisas. Entre esses ensinamentos, está a fluidez de uma contemporaneidade na qual as áreas de escuridão não podem ser olvidadas, pois, nas palavras de Agamben, "contemporâneo é aquele que recebe em pleno rosto o facho de trevas que provém do seu tempo". Entre espaços sombrios e nebulosos, a literatura passeia noturnamente por um bosque lírico-filosófico no qual se torna possível neutralizar as luzes dos relatos institucionalizados e historicizados. Ao navegar por essa perversa obscuridade, o passageiro contemporâneo é aquele que percebe o escuro do seu tempo como algo que lhe concerne e não cessa de interpelá-lo.

Ser contemporâneo é, antes de tudo, uma "questão de coragem", porque significa ser capaz não apenas de manter fixo o olhar no escuro da época, mas também de perceber nesse escuro uma luz que, dirigida para nós, distancia-se infinitamente de nós. Continuemos, então, lutando por uma ética contemporânea da palavra.

\section{Referências}

AGAMBEN, Giorgio (2009). O que é o contemporâneo? E outros ensaios. Tradução de Vinícius Nikastro Honesko. Chapecó: Argos.

ARISTÓTELES (1973). Ética a Nicômaco. Tradução de Leonel Vallandro e Gerd Borheim. Porto Alegre: Abril Cultural. (Coleção Os Pensadores).

BENJAMIN, Walter (2012). Sobre o conceito de história. In: BARRENTO, João. $O$ anjo da história. São Paulo: Autêntica. 
CANDIDO, Antonio (1995). Direito à literatura. In: CANDIDO, Antonio. Vários escritos. São Paulo: Duas Cidades.

GOTTSCHALL, Johnathan (2012). The storytelling animal. New York: Houghton Mifflin Harcourt.

RANCIÈRE, Jacques (2009). A partilha do sensível. Tradução de Mônica Costa Netto. São Paulo: 34.

RUSHDIE, Salman (2012). Haroun and the sea of stories. Londres: Penguin.

SARAMAGO, José (2008). Ensaio sobre a cegueira. São Paulo: Companhia das Letras. 